\title{
Longitudinal Perspectives on Fathers' Residence Status, Time Allocation, and Testosterone in the Philippines
}

\author{
Lee T. Gettler • Thomas W. McDade • \\ Sonny S. Agustin • Alan B. Feranil • \\ Christopher W. Kuzawa
}

Received: 25 June 2014 / Revised: 1 November 2014 / Accepted: 20 November 2014 /

Published online: 24 December 2014

(C) Springer International Publishing 2014

\begin{abstract}
Past paternal psychobiology research has focused almost exclusively on biological, residential fathers and the role of fathers as direct caregivers. Here, drawing on a large sample of Filipino men, we help to expand this research area by testing for relationships between fathers' testosterone, prolactin, and weekly hours in work, childcare, and recreation. Using longitudinal data collected when men were an average of 21.5 and 26.0 years old, we tested whether changes in fathers' investments in childcare and work interrelated with testosterone changes. We also assessed whether fathers' residence status affected paternal testosterone changes. Cross-sectionally, we did not find evidence that fathers' testosterone or prolactin varied based on work effort or weekly hours of childcare (all $p>0.1$ ). Fathers who increased their weekly involvement in childcare between baseline and follow-up experienced declines in testosterone, on average $(p<0.05)$. Men who transitioned from being non-fathers (baseline) to being new fathers residing with their children (follow-up) experienced significantly larger declines in both waking and evening testosterone, compared to men who were residential fathers at both time points (both $p \leq 0.0001$ ). Men who became new fathers but were not residing with their children also showed significantly greater declines in evening testosterone, relative to the comparison group $(p<0.05)$. Our results add confirmation and expansion of the notion that low paternal testosterone is linked to heightened father-child interaction and proximity, but leave open the possibility that
\end{abstract}

\footnotetext{
L. T. Gettler $(\bowtie)$

Department of Anthropology, University of Notre Dame, 636 Flanner Hall, Notre Dame, IN 46556, USA e-mail: lgettler@nd.edu
}

T. W. McDade $\cdot$ C. W. Kuzawa

Department of Anthropology, Northwestern University, Evanston, IL, USA

T. W. McDade • C. W. Kuzawa

Cells to Society (C2S): The Center on Social Disparities and Health, Institute for Policy Research,

Northwestern University, Evanston, IL, USA

\section{S. S. Agustin • A. B. Feranil}

USC-Office of Population Studies Foundation, University of San Carlos, Metro Cebu, Philippines 
fatherhood can also affect men's testosterone independent of whether they reside with their children.

Keywords Prolactin · Paternal care - Indirect care · Psychobiology · Residential father · Paternal investment

\section{Introduction}

Accumulating evidence indicates that human fathers are capable of accommodating the demands of parenthood through hormonal, neurobiological, and possibly also neural structural changes (Gettler 2014; Gray and Campbell 2009; Kim et al. 2014; Rilling 2013; Swain et al. 2014). There is growing interest in understanding the contextspecific expression of the biology of fatherhood, given the complexities of human parental care, which can include roles such as nurturant interactions, protective behaviors, and social-physical demands outside of the immediate family system (e.g. provisioning) (Gettler 2014; van Anders 2013). While research into the impacts of cultural and individual-level differences in human fathers' psychobiology is in its infancy, there is a longer history of work on paternal behavioral physiology among other vertebrate species with biparental care. Testosterone (T) and prolactin (PRL) are two hormones that are commonly assessed in such research, owing to their respective roles in male reproductive effort (T) and maternal behavior (PRL) (Gettler 2014; Ziegler 2000).

Among males, the testes are the principal source of $\mathrm{T}$, which is a steroid hormone that facilitates basic reproductive processes (e.g. spermatogenesis), sexually dimorphic physical characteristics (e.g. skeletal musculature) and behavioral patterns (e.g. malemale competition) that contribute to reproductive success for males of many mammalian species (Archer 2006; Bribiescas 2001; Gettler et al. 2010; Ketterson et al. 1992; McLachlan et al. 1996). PRL is a protein hormone that is primarily produced by the anterior pituitary and that plays a role in priming mammalian mothers for maternal care (alongside steroid hormone increases) during pregnancy, in addition to its imperative role in lactation (Freeman et al. 2000). Across vertebrate species in which biparental care has evolved, males commonly show reduced T and/or elevated PRL during periods in which offspring are dependent on parental care, although notable exceptions exist among rodents, primates, and other taxa (Gettler 2014). It is hypothesized that these paternal hormonal profiles reflect past selection pressures on fathers to nurture and invest in their offspring (facilitated by low T and/or high PRL) and engage in less malemale competition (Gettler 2010, 2014; Gray and Anderson 2010). There is some crossspecies evidence that reduced $\mathrm{T}$ can have a paternal care-facilitating, competitionreducing effect but less explicit support for the importance of elevated PRL to invested fathering behavior, though the interface of PRL and male social behavior is comparatively understudied (Gettler 2014).

To date, only a small number of studies have examined human paternal PRL. Three studies have tested for differences in PRL based on men's parenting status. Gray et al. (2007) found no differences between fathers and non-fathers in Jamaica, and first-time expectant fathers and partnered cohabitating non-fathers did not differ for PRL in a Canadian study (Delahunty et al. 2007). Working with a large longitudinal cohort in the Philippines, we recently showed that fathers had higher PRL relative to non-fathers 
(Gettler et al. 2012a). In our study, fathers of infants ( $\leq 1$ year old) had the most elevated PRL, but we found no differences in PRL based on fathers' level of self-reported caregiving (Gettler et al. 2012a). Data from other cultural settings provide mixed evidence for the hypothesis that PRL will promote a nurturant paternal phenotype. Compared to their lower PRL peers, Canadian fathers with higher basal PRL reported more concern when hearing infant cries (Fleming et al. 2002), but a recent fMRI study of US fathers found no relationship between PRL and fathers' neural responses in the anterior insula, the activation of which relates to empathy, when listening to infant cries (Mascaro et al. 2013b). Elsewhere, Israeli fathers with greater PRL engaged in longer bouts of exploratory play with their infants during observations (Gordon et al. 2010). While we know very little about PRL's interface with other parenting or male social behaviors among humans, studies of paternal PRL in some bird species are consistent with the possibility that it facilitates indirect forms of paternal investment (e.g. provisioning) as well as direct forms of care (Gettler 2014; Ziegler 2000).

In contrast, $\mathrm{T}$ has been a focus of male psychobiological research for decades (Archer 2006; Mazur and Booth 1998). Much of the early research on human paternal psychobiology focused on applying tenets of the (ornithological) "Challenge Hypothesis" to humans by testing whether partnered fathers had lower $\mathrm{T}$ than partnered non-fathers and single men (Gray et al. 2002; Gray 2003; Gray et al. 2006). While patterns vary between- and withincultures (Gray and Campbell 2009; van Anders 2009), multiple cross-sectional and longitudinal studies have found evidence consistent with the idea that men's $\mathrm{T}$ often declines as they transition to long-term committed partnerships and become fathers (Booth and Dabbs 1993; Gettler et al. 2011a; Gray et al. 2002, 2006; Hooper et al. 2011; Mazur and Michalek 1998; Perini et al. 2012), though scholars have also argued that men's $\mathrm{T}$ drives relationship orientation-status, rather than responding to it (cf. van Anders and Goldey 2010). Past studies of paternal physiology were generally limited to biological residential fathers (but see Gray et al. 2007), leaving much unknown about the psychobiological correlates of other father-child relationships, such as non-residential, adoptive, and step fathers.

More recent research has tested the hypothesis that fathers who were more invested in their children, particularly in day-to-day direct (hands-on) caregiving, would have lower $\mathrm{T}$ than non-involved fathers, thus positing father-child contact as a possible mechanistic pathway through which low paternal $\mathrm{T}$ emerges (Alvergne et al. 2009; Gettler et al. 2011a, 2012b; Gray et al. 2002; Muller et al. 2009). Support for this model has emerged from diverse cultural settings, with fathers who perform care having lower $\mathrm{T}$ than non-caregiving fathers or those who are rated low for paternal investment (by mothers) (Alvergne et al. 2009; Gettler et al. 2011a, 2012b; Mascaro et al. 2013a; Muller et al. 2009). Evidence from laboratory-based research studies in which fathers directly interact with their children or men are exposed to infant-stimuli (e.g. recorded cries) also provide support for the idea that low $\mathrm{T}$ fathers are more sensitive to infant cues and are more nurturant during father-child contact, compared to high $\mathrm{T}$ fathers (Fleming et al. 2002; Storey et al. 2011; van Anders et al. 2012; Weisman et al. 2014).

Yet, there are a number of limitations in the existing research on human $\mathrm{T}$ and fathers' behavior, especially that conducted under naturalistic, non-laboratory conditions. While invested, caregiving fathers tend to have lower $\mathrm{T}$ than fathers not involved 
in care, comparisons in the majority of relevant studies are based on categorical distinctions of "no/low care" versus "any/high care" or, in our study using nighttime proximity as proxy for care, "solitary sleeping" versus "cosleeping" (Alvergne et al. 2009; Gettler et al. 2011a, 2012b; Kuzawa et al. 2009). As a further example, Muller et al. (2009) conducted a study comparing men's T in two, neighboring East African groups, with samples drawn from Hadza (foragers, fathers involved in direct care) and Datoga, (pastoralists, fathers not principally involved in care) subjects. Among the Datoga, fathers and non-fathers did not differ in T, whereas the Hadza fathers had lower $\mathrm{T}$ than their non-father counterparts, suggesting that cultural norms of paternal care contributed to variation in male $\mathrm{T}$ (Muller et al. 2009). Yet, based on rigorous, direct behavioral observations, Hadza fathers perform relatively little daytime direct childcare as a percentage of their total daily activities, although they do cosleep (Marlowe 1999, 2005). Fathers in other cultural contexts commonly spend little-to-no time in direct care, especially compared to mothers (Hewlett 1992; Shwalb et al. 2013).

At present, both proximate and ultimate questions of why human males' T production appears to be so sensitive to investment in childcare remain unsettled. van Anders et al. (2011) recently proposed model in which low $\mathrm{T}$ is linked to expressions of warmth and nurturance, which provides a theoretical framework for framing hypotheses regarding $\mathrm{T}$ and daily father-child interactions. However, given that fathers commonly play such a subsidiary role in that parenting domain, it is plausible that childcare is serving as a proxy for another social or demographic factor related to variation in paternal T (Gettler 2014). For example, it is possible that fathers who engage in childcare may participate in fewer day-to-day competitive interactions with other men (Gettler 2014), given that competition is known to increase men's T (in the short-term, at least) (Archer 2006; van Anders 2013).

Very little is currently known about how a father's T relates to his behaviors in other parenting and social domains, despite the fact that human parents' social interactions outside of their immediate family system likely have varied and, at times, opposing influences on the same hormones. In most cultural settings fathers' primary parental investment behaviors are indirect, such as provisioning of calories or other physical resources (Hewlett 1992; Shwalb et al. 2013), and such paternal roles are thought to have been evolutionarily important in terms of the emergence of human's life history and fertility patterns (Hill and Hurtado 2009; Kaplan et al. 2000). There is growing interest in the psychobiological underpinnings of these indirect parenting behaviors, i.e. with avian PRL research providing a preliminary foundation to test such hypotheses (Gettler et al. 2012a; Gettler 2014). For example, Jasienska et al. (2012) hypothesized that low socioeconomic status Polish fathers' $\mathrm{T}$ increased as their number of children went up because larger family size required them to compete more intensely for resources. Meanwhile among Tsimane horticulturalists in lowland Bolivia, men's T was found to acutely spike after a successful hunt, which the authors suggested might reinforce men's commitment to provisioning (Trumble et al. 2014). Elsewhere, US fathers' T did not vary based on their work hours (Mascaro et al. 2013a). Of course, childcare and provisioning/working do not encapsulate the entirety of fathers' daily activities (Gray and Anderson 2010), but, to our knowledge, no prior study has evaluated paternal psychobiological profiles and involvement in non-parenting behaviors, such as social interactions (with men and women) outside their family system. Existing psychobiological theory provides a basis for conceptualizing how day-to-day 
competitive interactions, as might occur in the work place, during provisioning activities, or social activities (e.g. playing/watching sports), could lead to upregulation of paternal T (Archer 2006; van Anders et al. 2011; van Anders 2013).

Here, we hope to help address some of these issues by analyzing demographic (fathers' residential status), behavioral, and hormonal (T, PRL) data from a large cohort of same-aged young adult men in Metro Cebu, Philippines. We collected these data during two surveys, in 2005 and 2009, when the men were 21.5 to 26.0 years old. Research in other settings suggests that whether fathers live with their children or not greatly affects their parenting behaviors (e.g. Anderson et al. 1999; Flinn 1992) and we hypothesized fathers' residence status might also impact paternal psychobiology. Here, we present a tiered set of analyses. First, we stratified fathers according to whether they were residential or non-residential parents and tested for group differences in weekly hours devoted to work for pay, childcare, and recreation. Second, using time allocation data collected at baseline (2005), we tested whether men's weekly time in paid work and recreation predicted their T and PRL and whether parenting status moderated those relationships. Among fathers, we also tested whether T was lower and PRL was higher among men reporting more weekly hours of paternal care. Drawing on data from both baseline and follow-up studies, we then conducted a preliminary set of longitudinal analyses for paternal care and fathers' work hours to assess whether changes in time spent in these activities between baseline and follow-up related to fathers' shifts in $\mathrm{T}$ over the same time period. Finally, drawing on T and demographic data collected at two time points, we tested for longitudinal effects of both life history transitions (becoming a new father) and paternal residence (whether men reside with their children or not) on men's T.

\section{Materials and Methods}

\section{Study Population and Sample Selection}

Data come from the Cebu Longitudinal Health and Nutrition Survey (CLHNS), a population-based birth cohort study of mothers and their infants born in 1983-84 (Adair et al. 2011). During the 2005 survey, CLHNS researchers located and interviewed 1008 males of the original cohort of 1633 liveborn males. Of these, 998 individuals had full in-home interview data, and their average age was $21.5 \pm 0.3$ (SD) years at the time of data and sample collection. The majority of subjects agreed to participate in blood $(n=889)$ and saliva $(n=869)$ sample collection and had complete questionnaire and biomarker data. During the 2009 survey, CLHNS researchers interviewed 908 males. Of these, 906 individuals had full in-home interview and saliva sample data, and they were a mean of 25.9 years old $( \pm 0.3)$ at the time of data collection.

\section{Socio-demographics}

CLHNS researchers conducted in-home interviews in the local dialect (Cebuano), during which they collected socioeconomic, demographic, and behavioral data (Adair et al. 2011). We defined men as partnered if they reported being married or 
cohabitating. In the 2005 CLHNS data collection, men reported their household composition, including the presence of their sons or daughters. We characterized men living with their child(ren) as "residential fathers." In 2005, men did not report whether they had offspring who were not residing with them. We therefore defined men as "non-residential fathers" if they reported (in 2009) being fathers in 2005 but did not report living with their child in the 2005 interview and reported having impregnated a woman in the past (in 2005). During the 2009 survey, fathers directly reported whether they were presently living with their children or not. Among fathers (2009), $99 \%$ reported having at least one biological child. Thus, the number of "residential fathers" living with step- or adopted children only is quite small $(n=5)$, and we did not make differentiations based on biological relatedness in our analyses. The Institutional Review Boards of the University of North Carolina, Chapel Hill and Northwestern University provided human subjects clearance under conditions of informed consent for this research.

\section{Time Allocation Data (2005)}

During the 2005 in-home interview, subjects reported their usual activities on both a routine working/school day and a non-working, non-school day, including their typical wake and bed times. In the activity recall, the subjects began with their first activity after waking and proceeded to quantify time spent in daily activities (minutes) until bedtime. Activities were then grouped according to the following categories: personal hygiene, child/parent care, food preparation (including eating), housekeeping, tending animals/gardens, working for pay (at home), working for pay (outside of home), recreation, schooling, studying, administering medicine. These activity categories have been used in this study for multiple decades and the data are not available in a format that would allow us to flexibly partition them into other categories or sub-categories for the present analysis (Adair et al. 2011). We also calculated sleep time from men's usual wake and bed times.

Men also reported the number of days per week that they worked or went to school. A small number of participants (1.4\% of the total sample) reported working and going to school and reported more school (in class) days than work days. For these men, we used their school day count in our time allocation calculations. We used the work/school day counts and the time allocation data for working and non-working days to produce variables for total time allocation per activity per week (in hours). Thus, our time allocation variables (quantified as weekly hours) take into account how many work days and non-work days the subjects have during a typical week. Here we focus on weekly time devoted to childcare, paid work, and recreation and label other time allocations as sleep or "other" (weekly hours not attributed to the prior four activities). The following are examples, taken directly from the CLHNS data codebooks, showing the types of behaviors that the activity codes subsume: childcare (bathing/cleaning, dressing up, putting to sleep/waking, bringing to and from school, helping with homework, taking for a walk); work for pay (getting wares ready for selling, opening/closing store, watching store, doing other people's laundry, getting ready for work, traveling to work, working); recreation (napping, reading, listening to the radio, watching TV/movie, 
gambling, smoking, praying, looking for head lice, embroidering, talking with neighbors). The full 2005 CLHNS demographic/behavioral questionnaires and data are publicly available online (http://www.cpc.unc.edu/projects/cebu/ datasets).

Comparable time allocation data were not collected in 2009. While we have data on recent time spent in work and paternal care (below) from 2009, we collected no data on men's recreation activities.

\section{Prior Week's Paternal Care and Work Hours (2009)}

In 2009, subjects reported the number of hours they worked in the week prior to their interview. Fathers also reported their involvement during the past week in 20 paternal caregiving behaviors, which were drawn primarily from a previous large-scale survey on male parenting behaviors in the Philippines. Examples of the caregiving behaviors included: feeding children, playing, bathing children, reading to children, putting children to sleep, and walking children to school (Gettler et al. 2011b, 2012b).

\section{Salivary $T$}

Subjects followed the same saliva collection procedures in 2005 and 2009. We provided each participant with instructions and two polypropylene tubes for saliva collection. Subjects provided their first sample immediately prior to bed (PM). After collection, they sealed the tube and kept it at room temperature. Mean PM sampling times were 10:46 PM $\pm 2: 44$ (2005) and 10:03 PM $\pm 2: 12$ (2009). Subjects placed the second tube next to their bed and collected the second sample immediately upon waking the following morning (AM). Mean AM sampling times were 6:50 AM $\pm 2: 05$ (2005) and 6:41 AM $\pm 1: 39$ (2009). Later on the second day, research staff retrieved the saliva tubes, placed the tubes on ice packs in a cooler while in transit to freezer storage at $-35 \mathrm{C}$, and later shipped the samples on dry ice to the Laboratory for Human Biology Research (LHBR) at Northwestern University, where they were stored at $-80 \mathrm{C}$. We assayed the saliva samples for $\mathrm{T}$ at the LHBR using an immunoassay protocol developed for use with saliva samples (Salimetrics, State College, PA; Kit No. 1-2402). Interassay coefficients of variation were 13.7 and $11.5 \%$ for high $(200 \mathrm{pg} / \mathrm{ml})$ and low $(20 \mathrm{pg} / \mathrm{ml})$ kit-based control samples, respectively, in 2005 samples and 7.8 and $17.9 \%$ for high and low control samples, respectively, in 2009 samples. We excluded four men based on salivary $\mathrm{T}$ values that were $6+\mathrm{SD}$ above the sample mean, suggesting possible blood contamination.

\section{Dried Blood Spot PRL}

From fasting, morning blood samples, single drops of whole blood were applied to Whatman protein cards for dried blood spot (DBS) analysis. The DBS samples dried at room temperature and were then frozen until shipment on dry ice to Northwestern University, where they were stored at $-80 \mathrm{C}$ until 
analysis. We selected a sub-sample of men with full questionnaire and dried blood spot sample data $(n=304)$ and assayed their DBS samples for PRL at the LHBR at Northwestern University. We used a commercially available immunoassay kit designed to measure PRL from serum (Diagnostic Systems Laboratories \# 104500). We modified this assay for use with DBS based on a previously published, validated protocol for the same procedure (Gettler et al. 2012a; Gray et al. 2007). The inter-assay coefficients of variation for PRL were 10.8 and $24.9 \%$ for high and low control samples, respectively. The CLHNS did not collect blood samples in 2009, thus we only have PRL data for 2005.

\section{Statistical Analyses}

We conducted our analyses using version 12.1 of Stata (Stata Corporation, College Station, TX). We analyzed T ( $\mathrm{pg} / \mathrm{ml})$, PRL ( $\mathrm{ng} / \mathrm{ml})$, educational attainment, number of children, age of youngest child, total sleep time, and time allocation activities as continuous variables. We adjusted AM and PM T and PRL for sampling times prior to our analyses. We used adjusted $T$ values to calculate absolute change in $T(\Delta T)$ between baseline (2005) and follow-up (2009) (Gettler et al. 2012b). Please see Gettler et al. 2013 for our rationale for using absolute $\Delta \mathrm{T}$ for CLHNS analyses.

We first compared fathers, stratified according to residence status, on a series of socioeconomic, demographic, and behavioral variables using Wilcoxon rank sum tests, t-tests, or chi-squared tests (Table 1). We tested for relationships between the time allocation variables (work, childcare, and recreation hours per week) using (nonparametric) Spearman correlations (rho), as the time activity data were non-normally distributed. We then used linear regression to predict men's PRL and T from work and recreation time and tested whether fatherhood status moderated those relationships. Among fathers, we also tested whether weekly involvement in paternal care (at baseline) predicted $\mathrm{T}$ and PRL.

Because the 2005 and 2009 data on time spent in paternal care and work were evaluated with different techniques (see above), we could not directly calculate the change in weekly hours spent in the activities between the two time points. Instead, we used z-scores of activity at each time point to gauge an individual's population rank with respect to childcare or work hours. For example, change in paternal care z-score between 2005 and 2009 then indicates a change in care effort relative to peers, with a positive change indicating relatively more time spent on care than peers, a negative change indicating a lag relative to peers, and no change as stability in relative paternal care effort. In separate models for child care and work hours, we predicted $\Delta \mathrm{T}$ from these change in z-score variables and controlled for relevant covariates (partnering status, residential status, number of children, age of youngest child).

Finally, we assessed whether fathers' $\Delta \mathrm{T}$ differed based on their residential status between baseline (2005) and follow-up (2009), including non-fathers (baseline) who became new fathers (follow-up) and the impact of changes in residence status for men who were already fathers at baseline. In subsequent models, we controlled for relevant covariates (partnering status, change in total sleep time, paternal care, number of children, age of youngest child). We set statistical significance at $p \leq 0.05$ with relationships between $p>0.05$ and $p<0.10$ interpreted as a borderline statistical trend. 
Table 1 Sample characteristics stratified according to fathers' residence status

\begin{tabular}{|c|c|c|c|c|c|c|c|}
\hline & \multicolumn{2}{|c|}{ All subjects } & \multicolumn{2}{|c|}{ Non-residential fathers } & \multicolumn{2}{|c|}{ Residential fathers } & \multirow[t]{2}{*}{$p$ value } \\
\hline & Mean & SD & Mean & $\mathrm{SD}$ & Mean & SD & \\
\hline \multicolumn{8}{|l|}{ Demographic characteristics $^{\mathrm{a}}$} \\
\hline age $\left(\right.$ years) ${ }^{\mathrm{a}}$ & 21.48 & 0.31 & 21.57 & 0.25 & 21.51 & 0.33 & 0.5 \\
\hline education (highest grade) $^{\mathrm{a}}$ & 9.78 & 3.33 & 9.00 & 2.18 & 8.55 & 3.14 & 0.6 \\
\hline 2005 partnered $(\% \mathrm{y})^{\mathrm{a}}$ & 19.5 & - & 42.9 & - & 96.1 & - & 0.001 \\
\hline 2009 partnered $(\% \mathrm{y})^{\mathrm{b}}$ & 52.8 & - & 29.5 & - & 99.2 & - & 0.001 \\
\hline \multicolumn{8}{|l|}{ Hormone values } \\
\hline 2005 salivary AM T $(\mathrm{pg} / \mathrm{ml})^{\mathrm{c}}$ & 191.88 & 76.20 & 228.48 & 70.16 & 161.75 & 62.39 & 0.001 \\
\hline 2005 salivary PM T $(\mathrm{pg} / \mathrm{ml})^{\mathrm{c}}$ & 117.61 & 52.24 & 125.43 & 51.16 & 95.53 & 40.54 & 0.02 \\
\hline 2009 salivary AM T (pg/ml $)^{\mathrm{b}}$ & 161.72 & 63.20 & 173.41 & 69.83 & 151.95 & 58.25 & 0.01 \\
\hline 2009 salivary PM T (pg/ml $)^{\mathrm{b}}$ & 95.46 & 42.90 & 99.31 & 40.05 & 88.48 & 41.82 & 0.06 \\
\hline prolactin $(\mathrm{ng} / \mathrm{ml})^{\mathrm{d}}$ & 11.77 & 4.43 & 15.74 & 8.24 & 12.46 & 4.25 & 0.11 \\
\hline \multicolumn{8}{|c|}{2005 time allocation (hours per week) , $^{\mathrm{a}, \mathrm{e}}$} \\
\hline recreation & 52.88 & - & 70.23 & - & 37.33 & - & 0.001 \\
\hline sleep time & 62.00 & - & 63.50 & - & 61.00 & - & 0.7 \\
\hline work & 21.25 & - & 0.00 & - & 48.50 & - & 0.007 \\
\hline childcare & - & - & 0.00 & - & 2.92 & - & 0.01 \\
\hline \multicolumn{8}{|c|}{2009 activity time (hours in the prior week) ${ }^{\mathrm{e}}$} \\
\hline work & 29.03 & - & 15.00 & - & 42.00 & - & 0.008 \\
\hline childcare & - & - & 0.00 & - & 16.00 & - & 0.001 \\
\hline
\end{tabular}

${ }^{a}$ Data from 2005 ( $\left.n=998\right)$, unless otherwise noted. 2005: non-residential fathers $(n=14)$, residential fathers $(n=127)$

${ }^{\mathrm{b}} n=904.2009$ : non-residential fathers $(n=61)$, residential fathers $(n=389)$

${ }^{\mathrm{c}} n=866$. non-residential fathers $(n=13)$, residential fathers $(n=114)$

${ }^{\mathrm{d}} n=304$. non-residential fathers $(n=5)$, residential fathers $(n=83)$

${ }^{\mathrm{e}}$ We present median values for the weekly activity variables

\section{Results}

Table 1 presents descriptive statistics for the entire sample and also stratified based on fathers' residence status. Residential and non-residential fathers did not differ for educational attainment $(p>0.6)$. At both time points, residential fathers reported more weekly hours working and caring for their children, compared to non-residential fathers (all $p<0.01$; Figs. 1 and 2). Residential fathers also engaged in less weekly recreation at baseline $(p \leq 0.01)$. The groups did not differ significantly for routine sleep hours at either time point (both $p>0.8$ ). At both baseline and follow-up, residential fathers were married/cohabitating at higher rates than non-residential fathers (both $p<0.01$ ). Fathers' PRL did not differ based on residence status $(p>0.1)$, though the comparison was limited by the small number of non-residential fathers with PRL data. Consistent with our hypotheses, residential fathers' AM T (2005 \& 2009) and PM T (2005) were 

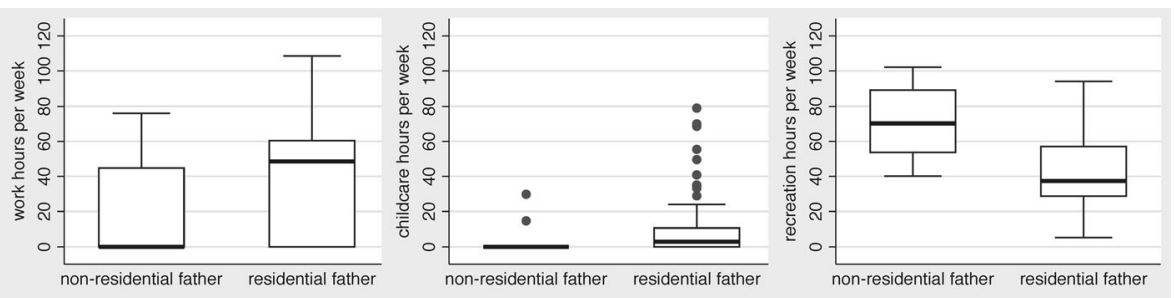

Fig. 1 Box and whiskers plots of residential and non-residential fathers' weekly hours of paid work, childcare, and recreation. On a weekly basis, residential fathers worked more hours, engaged in more childcare, and spent fewer hours in recreation compared to non-residential fathers (all $p<0.01$ ). The dark line on each box (interquartile range) indicates the group's median value

significantly lower than non-residential fathers' $\mathrm{T}$ (all $p<0.05$ ). The group comparison for 2009 PM T approached significance $(p=0.06)$.

Drawing on the 2005 time allocation data for the entire sample $(n=998)$, we found that men who worked more per week engaged in fewer hours of recreation (Spearman $r h o=$ $-0.72 ; p<0.0001)$. When we focused solely on fathers, work and recreation time were similarly negatively correlated $(r h o=-0.71 ; p<0.0001)$. Fathers' caregiving did not significantly vary based on their recreation time $(r h o=-0.14 ; p=0.1)$, but fathers who worked more engaged in less childcare $(r h o=-0.23 ; p=0.006)$. This negative correlation was based primarily on fathers' work hours outside the home $(r h o=-0.22 ; p=0.01)$, whereas paid work in the home was not correlated to weekly care $(p>0.8)$. However, fathers' work and caregiving hours were not significantly correlated at follow-up $(p>0.4)$.

If fathers' hormones interrelate with activities related to resource acquisition (Trumble et al. 2013), then parenting status should moderate relationships between work hours and T and PRL. Specifically, one hypothesis is that invested fathers' T should increase as work hours rise, whereas the slope of the T-work relationship should be flat or less steep among non-fathers. If elevated paternal PRL and heightened resource acquisition activities co-occur, as some avian data suggest, then invested fathers' PRL should increase as time spent in work rises but this relationship should be absent among non-fathers. When we evaluated a work hours $\mathrm{X}$ fatherhood status interaction as a predictor of baseline AM T $(n=866)$, main effects for both weekly work hours $[\beta(95 \% \mathrm{CI}):-0.22(-0.41,-0.03) ; p=0.025]$ and fatherhood status $[\beta-30.15$ $(-52.89,-7.41) ; p=0.009$; model $\mathrm{R} 2=0.022]$ were significant, but the work hours $\mathrm{X}$ fatherhood interaction term was not $(p>0.5)$. Notably, the main effect for work hours
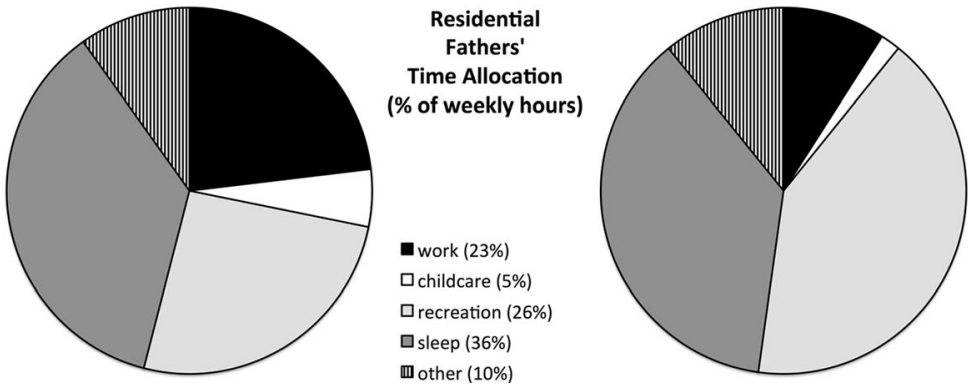

Non-residential

Fathers'

Time Allocation

(\% of weekly hours)

Fig. 2 Pie charts showing residential and non-residential fathers' time spent in paid work, childcare, recreation, sleep and other activities as percentages of their total weekly hours 
was in the opposite direction of our prediction. In models predicting PM T, there was a main effect for fatherhood status $[\beta-17.37(-32.98,-1.76) ; p=0.029]$ but no significant effect of work (main effect; $p>0.8$ ) or fatherhood X work interaction $(p>0.6)$. In a comparable model, there were no significant predictors of PRL $(p>0.9)$.

In contrast to the hypothesized moderating effect of fatherhood on hormonal-work correlations, we hypothesized that if our recreation variable relates to T and PRL, the slope would not vary based on parenting status. For example, if $\mathrm{T}$ increases with recreation time, possibly due, in part, to male-male social interactions, we anticipate that this relationship would hold regardless of parenting status. In our AM T model, there was a significant main effect for time spent in recreation $[\beta 0.24(0.02,0.45) ; p=$ 0.035 ; model R2 $=0.021$, but there was no significant main effect for fatherhood or the interaction between recreation hours X fatherhood (both $p>0.3$ ). For PM T, there was a main effect of fatherhood status $[\beta-29.44(-52.84,-6.03) ; p=0.014]$ but not for recreation or the interaction term (both $p>0.3$ ). There were no significant results in a comparable model for PRL (all $p \geq 0.1$ ). Cross-sectional models predicting baseline $\mathrm{T}$ and PRL from fathers' weekly hours of childcare were not significant (all $p>0.1$ ).

We then tested for longitudinal relationships between changes in paternal care, work hours, and fathers' $\Delta \mathrm{T}(n=104)$. We found no significant differences for fathers' $\triangle \mathrm{AM}$ or $\triangle \mathrm{PM} T$ based on relative changes in their work hours over the study period (both $p>0.3$ ). Meanwhile, fathers' who (relatively) increased their involvement in weekly care over the study period experienced larger declines in PM T over the same time period, compared to men whose relative caregiving decreased ( $p \leq 0.01$; Table 2 ; Fig. 3 ). This finding remained significant $(p<0.05)$ but the effect size $(\beta)$ declined modestly after we included changes in partnering status and residence status, which we hypothesized might confound the relationship (Table 2). After we included fathers' number of children and age of youngest child in the model, the effect size $(\beta)$ decreased mildly and the relationship between $\triangle \mathrm{PM}$ $\mathrm{T}$ and change in care became a statistical trend $(p=0.06$; Table 2$)$. There were no significant results for relative changes in care and $\triangle \mathrm{AM} T(p>0.5)$.

Expanding on the cross-sectional statistical comparisons in Table 1, we tested for longitudinal relationships between $\Delta \mathrm{T}$ and transitions to fatherhood and stratified by residence status (for non-fathers at baseline) or changes in residence status (for men who were fathers at baseline) $(n=360)$. In subsequent models, we controlled for covariates (partnering status, total sleep time, paternal care, number of children, and age of youngest child) that we hypothesized might contribute to or confound $\mathrm{T}$ differences between residential and non-residential fathers (Tables 3 and 4). We used residential fathers (baseline and follow-up) as the comparison group, anticipating that their $\mathrm{T}$ would remain relatively stable over the follow-up period, excepting a modest age-related decline (Gettler et al. 2011a). Men who transitioned from being non-fathers (baseline) to new residential fathers (follow-up) experienced significantly larger declines in AM and PM T relative to the comparison group (both $p<0.0001$ ). Adjustment for partnering status reduced the effect size $(\beta)$ though the results remained significant (both $p<0.05$ ). Both findings became statistical trends in the full model (both $p<0.1$; Tables 3 and 4). Subjects who transitioned from being non-fathers (baseline) to new non-residential fathers (follow-up) experienced significantly larger declines in PM T relative to the comparison group $(p=0.015)$. Although the finding was no longer significant $(p=0.07)$, the effect size $(\beta)$ was larger in the full model. Men who were non-residential fathers at baseline but became residential fathers by follow-up showed a 


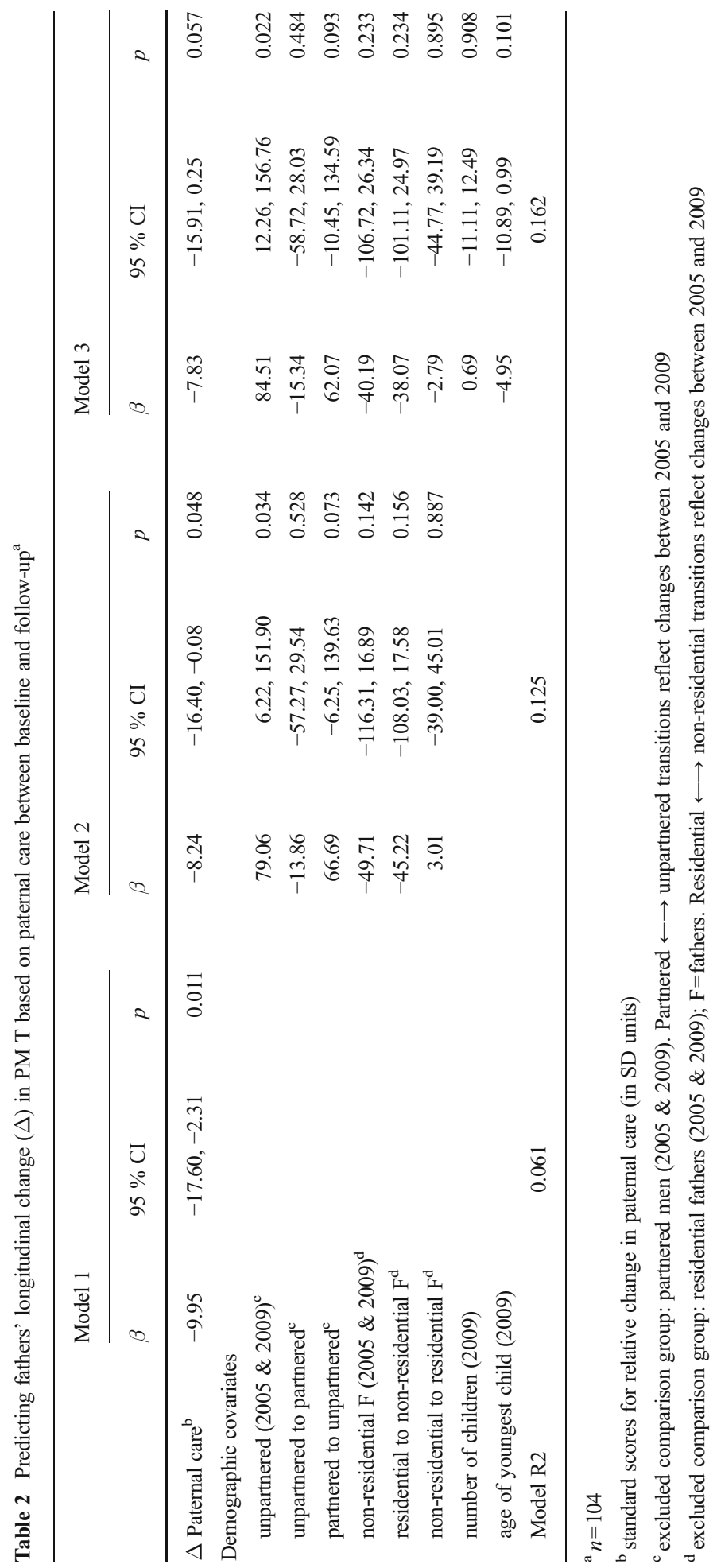




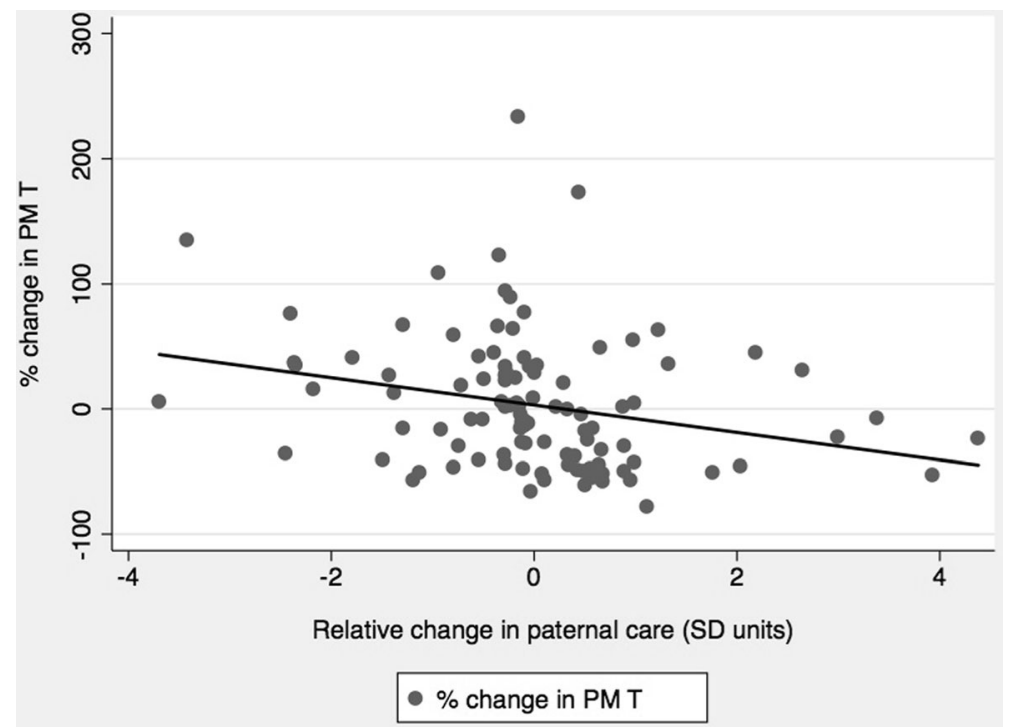

Fig. 3 Percentage (\%) change in fathers' evening (PM) testosterone $(\mathrm{T})$ based on relative change in paternal care between baseline and follow-up. We present percentage change in PM T for visual purposes, but used absolute change in $\mathrm{T}$ in our models (see Table 2). Change in paternal care z-score between baseline and follow-up indicates a change in care effort relative to peers (see Materials and Methods). Dark line=best fit linear relationship between percentage change in $\mathrm{T}$ and relative change in paternal care, $[\beta-10.95(-18.94$, $-2.96) ; p=0.008]$

larger decrease in AM T than men who remained residential fathers at both time points $(p=0.002)$, which remained significant in the full model. Other comparisons were not significant (all $p \geq 0.2$; Tables 3 and 4; Fig. 4).

\section{Discussion}

There is much interest in the effects that hormones such as T and PRL might have on men's parenting behaviors as well as the ways in which these hormones might also be regulated by social experiences (such as becoming an engaged father) (Gettler 2014; Rilling 2013; van Anders 2013). Past paternal psychobiology research has focused almost exclusively on biological, residential fathers and the role of fathers as direct caregivers. Thus, much remains unknown about the range of diverse circumstances and social contexts within which paternal psychobiology finds expression. Here, helping to advance the dialogue in these domains, we tested hypotheses regarding fathers' psychobiology, residence status, and their weekly time allocation. In cross-section, men's T and PRL either did not vary based on the amount of time they spent in childcare, work, and recreation or fatherhood did not moderate the relationships, which generally refutes our hypotheses. In longitudinal analyses, we found that men who increased their involvement in caregiving (relative to the distribution of their fellow fathers) experienced declines in $\mathrm{T}$, on average. In change models that incorporated both transitions to parenting and shifts in fathers' residence status, men who transitioned from being non-fathers (baseline) to being residential new fathers (follow-up) experienced larger declines in $\mathrm{T}$, compared to men who remained residential fathers at both 


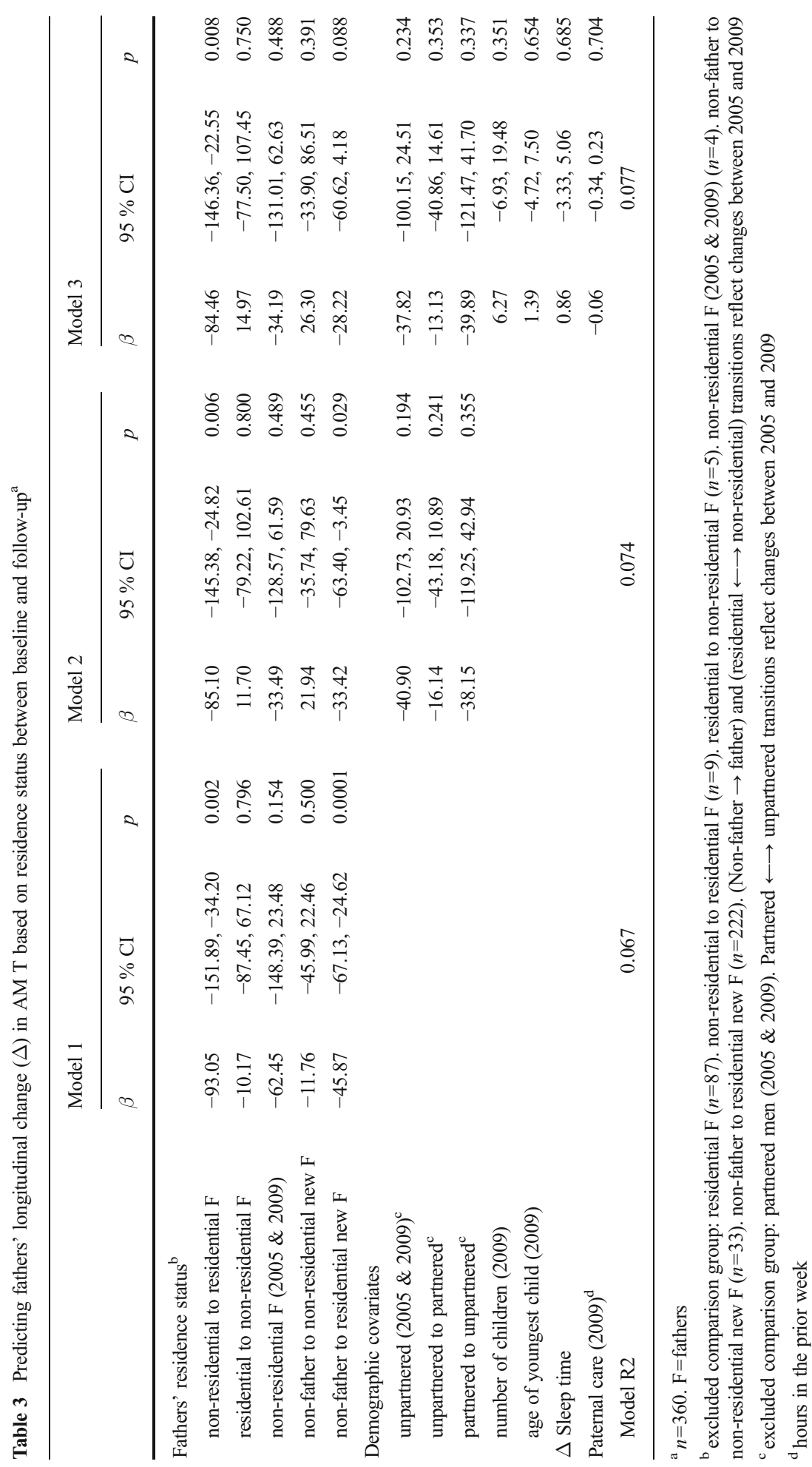




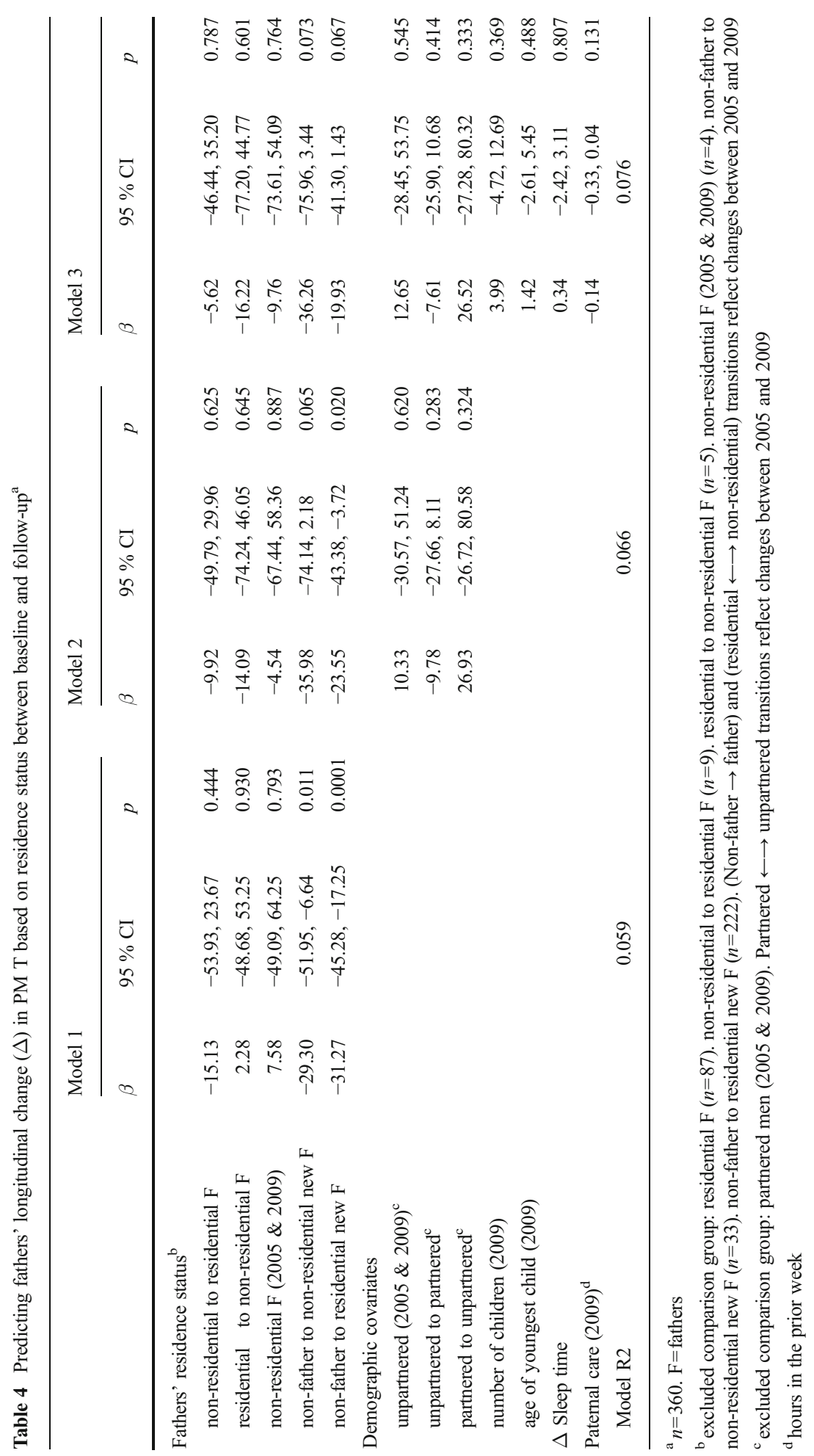




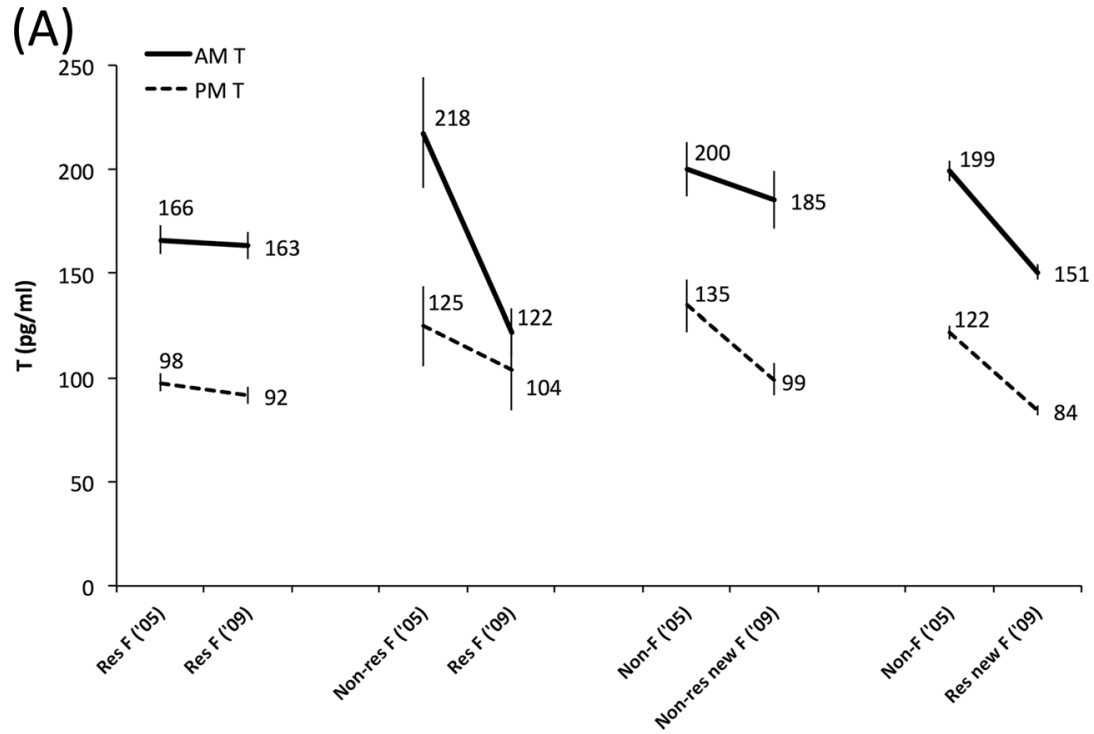

(B)

Group 1

Group 2

Group 3

Group 4

\section{Group 1 Group 2 Group 3 Group 4

$\begin{array}{cccc}\text { Res } & \text { Non-res F } & \text { Non-res } & \text { Res } \\ F & \text { to res F } & \text { new F } & \text { new F }\end{array}$

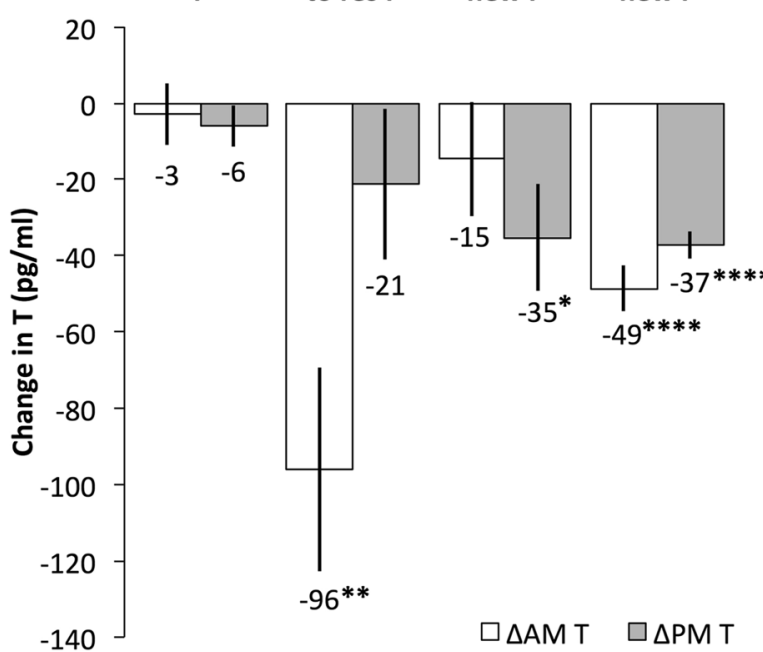

Fig. 4 Change in fathers' waking (AM) and evening (PM) testosterone (T) based on parenting status and residence status between baseline and follow-up. Res=residential. $\mathrm{F}=$ father. Group $1(n=87)$, residential fathers (both baseline and follow-up). Group $2(n=9)$, non-residential fathers (baseline) to residential fathers (follow-up). Group 3 ( $n=33$ ), non-father (baseline) to non-residential new father (follow-up). Group 4 ( $n=$ 222), non-father (baseline) to residential new father (follow-up). AM and PM T values were adjusted for time of saliva collection. a Within-group changes in AM and PM T values between 2005 and 2009. b Betweengroup changes in AM and PM T values between 2005 and 2009 based on parenting and residence status. Statistical comparisons are derived from regressing the change in $\mathrm{T}$ on changes in parenting and residence status, with Group 1 as the comparison group, ${ }^{*} p<0.05 ; * *<0.01 ; * * * * p \leq 0.0001$. Error bars indicate SEM 
time points. Relative to the comparison group, non-fathers who became non-residential new fathers also showed significantly larger declines in $\mathrm{T}$, as did men who transitioned from being non-residential fathers to living with their children. In highlighting the longitudinal relationships between fathers' residence status, paternal care, and T, our findings provide further support for a model in which father-child contact and proximity and declines in men's T as they become invested fathers potentially mutually reinforce one another.

Although cross-cultural data (outside of N. America, Europe, and Australia) on how fathers' allocate their time are fairly sparse and often employ diverse methodologies (time diary/allocation, behavioral scans, focal follows, etc.) (Gray and Anderson 2010), our baseline time allocation results are broadly consistent with those from other settings in which fathers partition their parenting effort between both direct and indirect care (Gray and Anderson 2010). In Cebu, we found that fathers who worked more hours were less involved in caregiving at baseline, although the effect size (rho) was relatively small. This suggests a modest trade-off between the two forms of investment. However, findings elsewhere are mixed in terms of whether fathers' economic/ productive activities impinge on their involvement in childcare (Barnett and Baruch 1987; Hill 2005; Marlowe 1999). Some time allocation studies from the US and Europe point to the importance of mothers' labor participation in shaping the quantity of fathers' childcare, more so than the absolute number of fathers' work hours (e.g. Barnett and Baruch 1987; Norman et al. 2014). Notably, we did not find that fathers who worked more performed less care at follow-up, at which point fathers were doing more weekly care, on average, compared to baseline, based on a visual inspection of Table 1 . Because fathers allocated relatively little of their weekly time to childcare at baseline ( $5 \%$ of time for residential fathers), it seems unlikely they were facing steep trade-offs between work and caregiving. Although speculative, it is possible that the negative relationship between the two activities no longer held because men's views on the complementarity of their work and childcare duties shifted as they matured between the ages of 21.5 and 26 years. For example, among the 119 men who were fathers at both time points and had full activity data, work and care were negatively related at baseline but were not at follow-up (results not shown).

Existing psychobiological theory and a large body of psychobiological research on T's short-term responsiveness to competition suggest that males who routinely engage in male-male competition might have elevated baseline T (van Anders et al. 2011; van Anders 2013; Archer 2006). We hypothesized that men who spent more time in recreation would have higher $\mathrm{T}$, because our recreation variable included social behaviors that could be related to male-male competition. Ethnographically, this hypothesis is applicable to our Cebuano sample because male peer groups ("barkadas") are important sources of camaraderie and outlets of male social activity. The nature of male interactions in those groups can often take on overt competitive tones, such as boasting, or be intertwined with competitive activities such as playing sports, gambling, or cockfighting (Dumont 1993; Guggenheim 1994). There was a main effect for men who engaged in more recreation to have higher waking T, although the effect sizes ( $\beta$ and R2) were small and the $\beta$ coefficient had a wide confidence interval. Fatherhood did not moderate this relationship, which was consistent with our hypothesis. Still, our broad measure of recreation was limited because it included many behaviors that we would not explicitly hypothesize would affect $\mathrm{T}$, which makes it difficult to interpret recreation's modest association with T here. As Gettler (2014) recently suggested and consistent with van 
Anders's (2013) nurturance-competition model, it remains unknown how fathers' exposure to routine competition relates to their $\mathrm{T}$ and how competition interrelates with other behaviors that correlate with $\mathrm{T}$, such as childcare. We anticipate being able to more rigorously test for such dynamics following the completion of an ongoing (2014-15) data collection in Cebu, which includes questions targeted to these issues.

In a hypothesis that is similarly grounded in a "high T-competition" theoretical background, it possible that fathers who engage in male-male competition in the context of resource acquisition will have elevated T compared to fathers less involved in such interactions (Jasienska et al. 2012; van Anders et al. 2011; van Anders 2013). Heretofore, few studies have explored T's relationship to economic/subsistence productivity. In their early, pioneering study, Worthman and Konner (1987) found no association between !Kung (Botswana and Namibia) foragers' $\mathrm{T}$ and hunting success. In research among Tsimane horticulturalists in lowland Bolivia, Trumble and colleagues have shown that males' $T$ acutely spikes during physically demanding tree chopping and plot clearing and during successful hunts (Trumble et al. 2013, 2014). The authors suggest that these physiological responses could enhance men's subsistence productivity (tree clearing) (Trumble et al. 2013), although this has not been specifically tested, and speculated that it might reinforce men's commitment to provisioning (hunting) (Trumble et al. 2014). These findings are generally consistent with theoretical predictions from van Anders et al. (2011), though Trumble et al. (2013) downplay the relevance of competition to their tree chopping findings. Elsewhere, US fathers' T did not vary based on their work hours (Mascaro et al. 2013a), similar to our longitudinal findings here. In cross-section, men who worked more in our sample had modestly lower AM T than men who worked less. Similar to our finding for recreation (above), we emphasize that the effect sizes ( $\beta$ and R2) were small and the $\beta$ coefficient had a wide confidence interval. Moreover, the large negative correlation between baseline work and recreation hours suggests that the separate significant main effects for AM T reflect covariance between work and recreation. Among men who were fathers at both time points, longitudinal shifts in work hours were not related to change in paternal $\mathrm{T}$ over the same time frame. In total, these results run counter to the hypothesis that high $\mathrm{T}$ facilitates paternal productivity in Cebu.

Overall, these results highlight the limitations of using work hours as proxy for paternal investment. In capitalistic societies, such as the US and the Philippines, fathers' ability to find work (especially in the Philippines) and the numbers of hours they work will often be outside of men's control, being subject to broader political economic-structural forces, and will vary by job placement. The nature of such questions in subsistence-level societies are no less complex, as labor specialization, familial wealth (i.e. among agrarian, pastoralist groups), ecological dynamics (e.g. lack of game for hunting, drought, etc.), and political economic factors (i.e. impingement of foragers' lands, forced relocation, influx of new technology) can all impact the extent to which fathers are able to work/provide, the nature of what they do in that regard, as well as (potentially) their psychobiology (Gray and Anderson 2010; Marlowe 2000; Shwalb et al. 2013). Regardless of whether one is focused on individuals in an industrialized or subsistence-level economy, most societies will include a diverse array of labor roles that vary in the extent to which they fall between highly competitive and mostly cooperative. Many labor specializations or jobs will routinely require social interactions in both domains. Without rich ethnographic or direct behavioral observation data on the 
nature of labor roles, it will remain challenging to make precise predictions regarding the psychobiology of production or resource acquisition. Although it does not circumvent those structural issues, Trumble's (2013) approach holds promise as it looks at proximate, short-term psychobiological shifts "in the moment" of production, as compared to our analyses here, which focus on reports of routine activity as predictors of baseline hormonal values.

Compared to the small number of studies on the relationship between $\mathrm{T}$ and paternal economic productivity, there is a growing body of cross-cultural research demonstrating that fathers who are more involved in direct childcare have lower $\mathrm{T}$ than less involved fathers (Alvergne et al. 2009; Mascaro et al. 2013a), including our prior analyses of men from this sample when they were 26 years old (Gettler et al. 2011a, $2012 b$ ). Here, we did not find variation in fathers' T based on men's weekly hours of care when they were 21.5 years of age. This finding generally aligns with prior results from this baseline survey, which showed that both non-caregiving and caregiving fathers had lower $T$ than non-fathers (Kuzawa et al. 2009). Thus, in our data from $\mathrm{Cebu}$, we find some potential inconsistencies between paternal care and $\mathrm{T}$ when the men were 21.5 years versus 26.0 years of age (Gettler et al. 2011a, 2012b; Kuzawa et al. 2009). What this suggests is that the relationship between paternal care and $\mathrm{T}$ in Cebu shifted as men aged. We can only speculate as to why this might be the case. It could relate to qualitative differences in the types of care that young versus older fathers perform, men's cognitive appraisals of their parenting behaviors and roles, or other family system dynamics, (e.g. co-parenting, alloparenting).

Broadly consistent with the idea that an interface between T-paternal care emerges in this sample as fathers move from their early to mid $20 \mathrm{~s}$, we found that fathers who increased their involvement in childcare (relative to other fathers) between baseline and follow-up experienced declines in evening $\mathrm{T}$, on average, whereas $\mathrm{T}$ rose among fathers who decreased their relative level of care. The effect size for the relationship was sufficiently large to suggest biological meaningfulness, as a 1 SD increase in caregiving corresponded to $\sim 11 \%$ decline in evening T. A detailed ethnographic overview of family systems and parenting in the Philippines is beyond the scope of our article (but see Medina 2001). Moreover, we do not have individual-level data on fathers' motivations or interpretations of their parenting behaviors that would inform a perspective on nurturance in this setting. That said, the types of direct, hands-on childcare behaviors on which fathers reported in our study, particularly at follow-up, are traditionally ascribed to mothers, whereas fathers' roles in the family have historically aligned with breadwinning and instilling moral values and behaviors (Medina 2001; Tan 1994). We are confident that, on average, fathers who are "going against the grain" in terms of cultural perceptions of parenting roles by providing such direct care to their children are often behaving nurturantly and are prioritizing engaged fathering in spite of likely conflicts with long-standing cultural conceptions of masculinity (Dumont 1993; Medina 2001; Tan 1994). Thus, we consider our results in line with existing psychobiological models regarding low $\mathrm{T}$ and sensitive-nurturant social interactions (van Anders et al. 2011; van Anders 2013; Gettler 2014).

The addition of control variables reduced the strength of the relationship between $\mathrm{T}$ and care, which became a statistical trend in the full model. This indicates confounding by changes in other factors over the study period, particularly fathers' partnering status, and suggests that shifts in other social dynamics, perhaps partner interactions or 
relationship quality, also longitudinally interrelate with fathers' $\mathrm{T}$. We only observed a longitudinal T-care relationship for evening T. This pattern is broadly consistent with our past results from this sample in which men's partnering and parenting transitions, men's sexual activity, and fathers' caregiving (including cosleeping) were all more strongly correlated to evening T compared to waking T (Gettler et al. 2011a, 2012b, 2013). Other scholars have proposed that morning $\mathrm{T}$ levels reflect circadian-sleep biology and are more impervious to social stimuli in humans and other hominoids whereas evening $\mathrm{T}$ is more responsive to social and behavioral context (Muller and Wrangham 2004).

Most prior relevant studies focusing on $\mathrm{T}$ and paternal care have cross-sectionally demonstrated that involved fathers have lower $\mathrm{T}$ than less involved fathers (Gettler et al. 2011a, 2012b; Alvergne et al. 2009; Mascaro et al. 2013a, b; Muller et al. 2009). Our prior research offered some longitudinal perspectives on childcare and fathers' $\mathrm{T}$ by demonstrating that men's pre-fatherhood $\mathrm{T}$ levels did not predict paternal care multiple years later (Gettler et al. 2011a) and that men who transitioned to fatherhood and subsequently practiced familial cosleeping experienced larger decreases in $\mathrm{T}$ (during the parenting transition), compared to solitary sleeping fathers (Gettler et al. 2012b). However, to our knowledge, our results here are the first longitudinal evidence of concomitant, linked, within-individual changes between $\mathrm{T}$ and paternal care. Our findings also present evidence for a continuous, negative relationship between $\mathrm{T}$ and paternal care, whereas, most prior, related studies have used categorical variables, such as "no/low care" versus "any/high care" or "solitary sleeping" versus "cosleeping," leaving questions open as to whether fathers' $\mathrm{T}$ might be sensitive to even minor amounts of direct care (Gettler 2014). In total, our within-individual, longitudinal modeling approach confers many analytical advantages, relative to cross-sectional analyses (Duncan et al. 1998), and provides robust confirmation of interface between direct paternal care and T. In particular, "change models" minimize the likelihood of confounding by unmeasured factors, because any permanent or stable factors that differ between men are eliminated as potential influences on change in T experienced during the period of follow-up (Duncan et al. 1998). However, we cannot explicitly determine the direction of the initial effect or, in other words, the precipitating cause linking increasing paternal care and declining $\mathrm{T}$ is unclear. Given that $\mathrm{T}$ can causally contribute to shifts in mood and behavior and T's production can be affected by social stimuli (van Anders et al. 2011), including in domains relevant to parenting and partnering (Gettler et al. 2011a, 2013), we hypothesize that shifts in paternal care and $\mathrm{T}$ bi-directionally influence another, leading to a cascading, reinforcing process through time.

In a set of complementary findings, we showed that men who transitioned from being non-fathers at baseline to being new fathers residing with their children at follow-up experienced significantly larger declines in both waking and evening $\mathrm{T}$, compared to men who were residential fathers at both time points. Notably, these findings both became statistical trends in our full models, with fatherhood-related variables and changes in partnering accounting for some of the relationship between $\mathrm{T}$ and fathers' residence status. In addition, men who were non-residential fathers at baseline but were living with their children at follow-up had significantly larger declines in waking $\mathrm{T}$, relative to the comparison group. We urge caution in interpreting this latter finding because the sub-sample size is small $(n=9)$, and it 
diverges from our prior results in being limited to waking T. As we mentioned above, our past research from this sample has shown stronger or sometimes exclusive relationships between evening $\mathrm{T}$ and social-behavioral variables, compared to waking T (Gettler et al. 2011a, 2012b, 2013). Our consistent findings (across waking and evening $\mathrm{T}$ ) for men becoming residential new fathers align with the possibility that fathers' social or emotional experiences of living with their children contribute to initial declines in their T, with partnering transitions also likely affecting men's $\mathrm{T}$ in addition to or independent of residence status, as has been shown in prior longitudinal research (Mazur and Michalek 1998; Gettler et al. 2011a).

However, adding complexity to this discussion, men who became new fathers but were not residing with their children also showed significantly greater declines in evening $\mathrm{T}$, relative to the comparison group. Although this result also became a statistical trend in the full model, indicating that shifts in partnering status and other fatherhood-related variables (i.e. number and age of children) accounted for some of the initial finding, it leaves open the possibility that fatherhood can affect men's $\mathrm{T}$ independent of whether they reside with them and controlling for their investments in childcare. In this cultural setting, the transition to fatherhood and the number of children men produce are a boost to perceptions of men's masculinity (Medina 2001), and we hypothesize that this is one possible social pathway through which fatherhood could affect $\mathrm{T}$, independent of co-residence/childcare. Specifically, new fathers might feel less need to prove their masculinity, thus abstaining from behaviors (such as competition with male peers) that might increase $\mathrm{T}$ production. This remains to be tested. In total, these issues parallel broader questions that we have highlighted in this article and elsewhere that remain to be answered regarding the social or environmental pathways through which father versus non-father as well as between-father variability in T emerges (Gettler 2014).

Finally, a small number of human psychobiological studies and an array of crossspecies data provide the impetus to test the hypothesis that fathers with elevated PRL will engage in more direct caregiving (Gettler 2014). Meanwhile, a small number of avian studies suggest elevated paternal PRL and heightened provisioning effort might co-occur (Gettler et al. 2012a). As applied to our sample, these likely represent alternative hypotheses regarding paternal investment and PRL, in light of the tradeoffs between fathers' time spent in work and care at baseline. Fathers' PRL did not differ based on their weekly childcare. This parallels our prior finding from this sample, in which fathers' PRL did not vary based on whether they reported being "mainly responsible for taking care of their children" or not (Gettler et al. 2012a). Yet, we did previously show that fathers have higher PRL than non-fathers in Cebu (Gettler et al. 2012a), which leads to hypotheses regarding functional implications, in light of PRL's role in paternal care in other species (Gettler 2014; Ziegler 2000). Because our childcare measure is broad and encompassing, it is plausible that it lacks sufficient details on specific behaviors for us to document correlations with PRL. For example, in Canada, fathers with high PRL were more responsive to infant cries (Fleming et al. 2002). Elsewhere, Israeli fathers with elevated PRL engaged in more stimulatory, exploratory play with their children, but their PRL did not correlate to father-infant affect during the behavioral observations (Gordon et al. 2010). In addition to our lack of data on specific care behaviors, our time allocation variables 
might not be sufficiently reliable and adequately powered to detect cross-sectional relationships with PRL. Alternatively, PRL release from the pituitary is downstream of dopamine and serotonin activity in the brain (Freeman et al. 2000), so perhaps elevated paternal PRL in this setting is an epiphenomenon with no functional implications for the quality/quantity of fathers' caregiving. We also did not find variation in PRL based on men's work time or moderation of the PRL-work hours relationship by parenting status, as would be found if elevated PRL and higher work output occurred only among fathers.

Our study has a number of limitations that merit discussion. Because we did not collect bloodspot samples at both baseline and follow-up, we were unable to evaluate longitudinal relationships between PRL, changes in men's parenting and residence status, and shifts in their work and childcare hours. Additionally, in our cross-sectional analyses, using the average of PRL from repeated samples, collected over several days from the same subjects, would have resulted in a more reliable estimate of each man's typical PRL level (Dabbs 1990). Moreover, the PRL assay method we used in this study is characterized by greater than ideal measurement error for low values of the hormone, as was also the case in the previous study in which this assay was validated (Gray et al. 2007). Our single bloodspot measurements and assay limitations do not introduce systematic bias, such as might increase the incidence of Type I errors, but do reduce the reliability of our PRL measures and thereby limit our ability to detect significant relationships. These limitations of our PRL data and the smaller sample of men for whom PRL data was available (compared to T) constrained our ability to conduct models integrating both PRL and T and to test for their potential joint effects on male psychobiology (van Anders et al. 2011). Nonetheless, understanding the psychobiological implications of multiple interacting peptide-protein and steroidal hormonal messengers, motivated by existing theory (van Anders et al. 2011), remains an important goal for studies in this domain, going forward.

In addition, prior to our analyses, the CLHNS time allocation data were grouped into categories that combine a diverse array of behaviors. Moreover, our time allocation approach asked men to recall the sequence of their "usual" activities on a typical work and non-work day. Time diary approaches more commonly involve recollection of the prior day's activity, which subjects are generally able to reconstruct with more accuracy than when they are asked to summarize activities for "typical" or "average" days. Direct observational methodological approaches (e.g. behavioral scans, focal follows) to collect time use data can also offer advantages and comparatively enhanced reliability and merit increased incorporation into psychobiological research (Bernard 1998; Robinson and Godbey 2010). In total, these methodological issues may have constrained our ability to detect significant cross-sectional correlations with PRL and stronger or more nuanced associations with $\mathrm{T}$. That we documented discrepancies between residential and nonresidential fathers for work, childcare, and recreation hours at baseline, as we predicted would be the case based on studies in other cultural settings, gives us confidence that our time allocation variables capture socially meaningful variation in men's day-to-day activities, though only in terms of broad categories. While we acknowledge that our longitudinal approach to change in relative rank for childcare and work hours between baseline and follow-up is not perfect, our results for $\Delta \mathrm{T}$ and shifts in paternal care highlight the strengths of within-individual, "change" models (Duncan et al. 1998), which can overcome some of the (cross-sectional) limitations of our time allocation data. 


\section{Conclusion}

In summary, in this sample of Filipino subjects, young adult fathers who worked more on a weekly basis engaged in fewer hours of weekly recreation and childcare. Residential fathers performed more weekly childcare and worked more hours, while spending less time in recreation, compared to non-residential fathers. In addition, we found somewhat conflicting evidence for the idea that men transitioning to living with their children leads to large declines in their T. On the one hand, we showed that men who transitioned from being non-fathers at baseline to being new fathers residing with their children at follow-up experienced significant large declines in both waking and evening $\mathrm{T}$. In a complementary finding, men who were non-residential fathers at baseline but were living with their children at follow-up also showed large declines in waking T. On the other hand, men who transitioned from being non-fathers at baseline to being new fathers who did not live with their children at follow-up experienced substantial decreases in evening T. Importantly, changes in partnering status over that same time period also confounded some of the effects for men who became new fathers. Finally, we found the first longitudinal evidence, to our knowledge, for concomitant, within-individual changes in men's caregiving effort and $\Delta \mathrm{T}$, with fathers who (relatively) increased their caregiving over the study period experiencing declines in T. Our results add confirmation and expansion of the notion that low paternal $\mathrm{T}$ is linked to heightened father-child interaction and proximity, and we argue that it is likely that nurturant expressions of paternal care are key to our findings in this cultural context (van Anders 2013). More broadly, our results help emphasize that parental psychobiology and its implications for parenting behavior intersect with developmental, demographic, and cultural factors, rather than being uniform phenomena.

Acknowledgments Linda Adair played a central role in designing and implementing the CLHNS survey from which these data and samples were obtained. Abet Bas was instrumental in helping to construct the time allocation data for this article. Dr. Elizabeth Quinn, Katy Sharrock, Jeffrey Huang, Iram Azam, Divya Mallampati, Brian Dubin, and Laura Rogers helped with various phases of lab work. Lauren Morisseau assisted with editing of the manuscript. Dr. James McKenna offered helpful comments on the manuscript. We thank the many researchers at the Office of Population Studies, University of San Carlos, Metro Cebu, Philippines, for their central role in study design and data collection, and the Filipino participants, who generously provided their time for this study.

Grant Information

Wenner Gren Foundation (Gr. 7356; Gr. 8186); National Science Foundation (BCS-0542182; BCS0962212); Interdisciplinary Obesity Center (RR20649) and the Center for Environmental Health and Susceptibility (ES10126; project 7-2004-E)

\section{References}

Adair, L. S., Popkin, B. M., Akin, J. S., Guilkey, D. K., Gultiano, S., Borja, J., Perez, L., Kuzawa, C. W., McDade, T., \& Hindin, M. J. (2011). Cohort profile: the Cebu Longitudinal Health and Nutrition Survey. International Journal of Epidemiology, 40(3), 619-625.

Alvergne, A., Faurie, C., \& Raymond, M. (2009). Variation in testosterone levels and male reproductive effort: insight from a polygynous human population. Hormones and Behavior, 56, 491-497. 
Anderson, K. G., Kaplan, H., \& Lancaster, J. (1999). Paternal care by genetic fathers and stepfathers I: Reports from Albuquerque men. Evolution and Human Behavior, 20(6), 405-431.

Archer, J. (2006). Testosterone and human aggression: an evaluation of the challenge hypothesis. Neuroscience and Biobehavioral Reviews, 30(3), 319-345.

Barnett, R. C., \& Baruch, G. K. (1987). Determinants of fathers' participation in family work. Journal of Marriage and Family, 49(1), 29-40.

Bernard, H. R. (1998). Handbook of methods in cultural anthropology. CA: Altamira Press Walnut Creek.

Booth, A., \& Dabbs, J. M. (1993). Testosterone and men's marriages. Social Forces, 72(2), 463-477.

Bribiescas, R. G. (2001). Reproductive ecology and life history of the human male. Yearbook of Physical Anthropology, 116, 148-176.

Dabbs, J. M. (1990). Salivary testosterone measurements: reliability across hours, days, and weeks. Physiology and Behavior, 48(1), 83-86.

Delahunty, K. M., McKay, D. W., Noseworthy, D. E., \& Storey, A. E. (2007). Prolactin responses to infant cues in men and women: effects of parental experience and recent infant contact. Hormones and Behavior, 51(2), 213-220.

Dumont, J.-P. (1993). The Visayan male“ barkada”: manly behavior and male identity on a Philippine island. Philippine Studies, 41(4), 401-436.

Duncan, G. J., Yeung, W. J., Brooks-Gunn, J., \& Smith, J. R. (1998). How much does childhood poverty affect the life chances of children? American Sociological Review, 63(3), 406-423.

Fleming, A. S., Corter, C., Stallings, J., \& Steiner, M. (2002). Testosterone and prolactin are associated with emotional responses to infant cries in new fathers. Hormones and Behavior, 42(4), 399-413.

Flinn, M. V. (1992). Paternal care in a Caribbean village. In B. S. Hewlett (Ed.), Father-child relations: Cultural and biosocial contexts (pp. 57-84). New York: Aldine de Gruyter.

Freeman, M. E., Kanyicska, B., Lerant, A., \& Nagy, G. (2000). Prolactin: structure, function, and regulation of secretion. Physiological Reviews, 80(4), 1523-1631.

Gettler, L. T. (2010). Direct male care and hominin evolution: why male-child interaction is more than a nice social idea. American Anthropologist, 112(1), 7-21.

Gettler, L.T. (2014). Applying socioendocrinology to evolutionary models: Fatherhood and physiology. Evolutionary Anthropology.

Gettler, L. T., Agustin, S. S., \& Kuzawa, C. W. (2010). Testosterone, physical activity, and somatic outcomes among Filipino males. American Journal of Physical Anthropology, 142(4), 590-599.

Gettler, L. T., McDade, T. W., Feranil, A. B., \& Kuzawa, C. W. (2011a). Longitudinal evidence that fatherhood decreases testosterone in human males. PNAS, 108(29), 16194-16199.

Gettler, L. T., Agustin, S. S., McDade, T. W., \& Kuzawa, C. W. (2011b). Short-term changes in fathers' hormones during father-child play: impacts of paternal attitudes and experience. Hormones and Behavior, 60(5), 599-606.

Gettler, L. T., McDade, T. W., Feranil, A. B., \& Kuzawa, C. W. (2012a). Prolactin, fatherhood, and reproductive behavior in human males. American Journal of Physical Anthropology, 148(3), 362-370.

Gettler, L. T., McKenna, J. J., Agustin, S. S., McDade, T. W., \& Kuzawa, C. W. (2012b). Does cosleeping contribute to lower testosterone levels in fathers? Evidence from the Philippines. PLoS ONE, 7(9), e41559.

Gettler, L. T., McDade, T. W., Agustin, S. S., Feranil, A. B., \& Kuzawa, C. W. (2013). Do testosterone declines during the transition to marriage and fatherhood relate to men's sexual behavior? Evidence from the Philippines. Hormones and Behavior, 64(5), 755-763.

Gordon, I., Zagoory-Sharon, O., Leckman, J. F., \& Feldman, R. (2010). Prolactin, oxytocin, and the development of paternal behavior across the first six months of fatherhood. Hormones and Behavior, 58(3), 513-518.

Gray, P. B. (2003). Marriage, parenting, and testosterone variation among Kenyan Swahili men. American Journal of Physical Anthropology, 122(3), 279-286.

Gray, P. B., \& Anderson, K. G. (2010). Fatherhood: Evolution and human paternal behavior. Cambridge: Harvard University Press.

Gray, P. B., \& Campbell, B. C. (2009). Human male testosterone, pair bonding and fatherhood. In P. T. Ellison \& P. B. Gray (Eds.), Endocrinology of social relationships (pp. 270-293). Cambridge: Harvard University Press.

Gray, P. B., Kahlenberg, S. M., Barrett, E. S., Lipson, S. F., \& Ellison, P. T. (2002). Marriage and fatherhood are associated with lower testosterone in males. Evolution and Human Behavior, 23(3), 193-201.

Gray, P. B., Yang, C. J., \& Pope, H. G. (2006). Fathers have lower salivary testosterone levels than unmarried men and married non-fathers in Beijing, China. Proceedings of the Royal Society B, 273(1584), 333-339. 
Gray, P. B., Parkin, J. C., \& Samms-Vaughan, M. E. (2007). Hormonal correlates of human paternal interactions: a hospital-based investigation in urban Jamaica. Hormones and Behavior, 52(4), 499-507.

Guggenheim, S. (1994). Cock or bull: Cockfighting, social structure, and political commentary in the Phillipines. In A. Dundes (Ed.), The cockfight: A casebook (pp. 133-173). Madison: Univ of Wisconsin Press.

Hewlett, B. S. (Ed.). (1992). Father-child relations: Cultural and biosocial contexts. New York: Aldine De Gruyter.

Hill, E. J. (2005). Work-family facilitation and conflict, working fathers and mothers, work-family stressors and support. Journal of Family Issues, 26(6), 793-819.

Hill, K., \& Hurtado, A. M. (2009). Cooperative breeding in South American hunter-gatherers. Proceedings of the Royal Society B, 276(1674), 3863-3870.

Hooper, A. E. C., Gangestad, S. W., Thompson, M. E., \& Bryan, A. D. (2011). Testosterone and romance: the association of testosterone with relationship commitment and satisfaction in heterosexual men and women. American Journal of Human Biology, 23(4), 553-555.

Jasienska, G., Jasienski, M., \& Ellison, P. T. (2012). Testosterone levels correlate with the number of children in human males, but the direction of the relationship depends on paternal education. Evolution and Human Behavior, 33(6), 665-671.

Kaplan, H., Hill, K., Lancaster, J., \& Hurtado, A. M. (2000). A theory of human life history evolution: diet, intelligence, and longevity. Evolutionary Anthropology, 9(4), 156-185.

Ketterson, E. D., Nolan, V., Wolf, L., \& Ziegenfus, C. (1992). Testosterone and avian life histories: effects of experimentally elevated testosterone on behavior and correlates of fitness in the dark-eyed junco (Junco hyemalis). American Naturalist, 140, 980-999.

Kim, P., Rigo, P., Mayes, L.C., Feldman, R., Leckman, J.F., Swain, J.E. (2014). Neural plasticity in fathers of human infants. Social Neuroscience, 1-14.

Kuzawa, C. W., Gettler, L. T., Muller, M. N., McDade, T. W., \& Feranil, A. B. (2009). Fatherhood, pairbonding, and testosterone in the Philippines. Hormones and Behavior, 56(4), 429-435.

Marlowe, F. (1999). Male care and mating effort among Hadza foragers. Behavioral Ecology and Sociobiology, 46(1), 57-64.

Marlowe, F. (2000). Paternal investment and the human mating system. Behavioural Processes, 51(1-3), 45-61.

Marlowe, F. (2005). Who tends Hadza children? In B. S. Hewlett \& M. E. Lamb (Eds.), Hunter-gatherer childhoods: Evolutionary, developmental, \& cultural perspectives (pp. 177-190). New Brunswick: Aldine Transaction.

Mascaro, J. S., Hackett, P. D., \& Rilling, J. K. (2013a). Testicular volume is inversely correlated with nurturing-related brain activity in human fathers. PNAS, 110(39), 15746-15751.

Mascaro, J.S., Hackett, P.D., Gouzoules, H., Lori, A., Rilling, J.K. (2013b). Behavioral and genetic correlates of the neural response to infant crying among human fathers. Social Cognitive and Affective Neuroscience.

Mazur, A., \& Booth, A. (1998). Testosterone and dominance in men. Behavioral and Brain Sciences, 21(3), $353-371$.

Mazur, A., \& Michalek, J. (1998). Marriage, divorce, and male testosterone. Social Forces, 77(1), 315-330.

McLachlan, R. I., Wreford, N. G., O’Donnell, L., de Kretser, D. M., \& Robertson, D. M. (1996). The endocrine regulation of spermatogenesis: independent roles for testosterone and FSH. Journal of Endocrinology, 148(1), 1-9.

Medina, B. (2001). The Filipino family. Quezon City: University of the Philippines Press.

Muller, M. N., \& Wrangham, R. W. (2004). Dominance, aggression and testosterone in wild chimpanzees: a test of the 'challenge hypothesis'. Animal Behaviour, 67, 113-123.

Muller, M. N., Marlowe, F. W., Bugumba, R., \& Ellison, P. T. (2009). Testosterone and paternal care in East African foragers and pastoralists. Proceedings of the Royal Society B, 276(1655), 347-354.

Norman, H., Elliot, M., \& Fagan, C. (2014). Which fathers are the most involved in taking care of their toddlers in the UK? An investigation of the predictors of paternal involvement. Community Work Family, $17(2), 163-180$.

Perini, T., Ditzen, B., Fischbacher, S., \& Ehlert, U. (2012). Testosterone and relationship quality across the transition to fatherhood. Biology Psychology, 90(3), 186-191.

Rilling, J. K. (2013). The neural and hormonal bases of human parental care. Neuropsychologia, 51(4), 731-747.

Robinson, J., \& Godbey, G. (2010). Time for life: The surprising ways Americans use their time. University Park: Penn State Press.

Shwalb, D. W., Shwalb, B. J., \& Lamb, M. E. (2013). Fathers in cultural context. New York: Routledge.

Storey, A. E., Noseworthy, D. E., Delahunty, K. M., Halfyard, S. J., \& McKay, D. W. (2011). The effects of social context on the hormonal and behavioral responsiveness of human fathers. Hormones and Behavior, 60(4), 353-361. 
Swain, J., Kim, P., Spicer, J., Ho, S., Dayton, C., Elmadih, A., Abel, K. (2014). Approaching the biology of human parental attachment: brain imaging, oxytocin and coordinated assessments of mothers and fathers. Brain Research.

Tan, A. J. (1994). Four meanings of fatherhood. Philippine Sociological Review, 42, 27-39.

Trumble, B. C., Cummings, D. K., O’Connor, K. A., Holman, D. J., Smith, E. A., Kaplan, H. S., \& Gurven, M. D. (2013). Age-independent increases in male salivary testosterone during horticultural activity among Tsimane forager-farmers. Evolution and Human Behavior, 34(5), 350-357.

Trumble, B. C., Smith, E. A., O’Connor, K. A., Kaplan, H. S., \& Gurven, M. D. (2014). Successful hunting increases testosterone and cortisol in a subsistence population. Proceedings of the Royal Society B, 281(1776), 1-8.

van Anders, S. M. (2009). Androgens and diversity in adult human partnering. In P. T. Ellison \& P. B. Gray (Eds.), Endocrinology of social relationships (pp. 340-363). Cambridge: Harvard University Press.

van Anders, S. M. (2013). Beyond masculinity: testosterone, gender/sex, and human social behavior in a comparative context. Frontiers in Neuroendocrinology, 34(3), 198-210.

van Anders, S. M., \& Goldey, K. L. (2010). Testosterone and partnering are linked via relationship status for women and 'relationship orientation' for men. Hormones and Behavior, 58(5), 820-826.

van Anders, S. M., Goldey, K. L., \& Kuo, P. X. (2011). The steroid/peptide theory of social bonds: integrating testosterone and peptide responses for classifying social behavioral contexts. Psychoneuroendocrinology, 36(9), 1265-1275.

van Anders, S. M., Tolman, R. M., \& Volling, B. L. (2012). Baby cries and nurturance affect testosterone in men. Hormones and Behavior, 61(1), 31-36.

Weisman, O., Zagoory-Sharon, O., \& Feldman, R. (2014). Oxytocin administration, salivary testosterone, and father-infant social behavior. Progress in Neuro-Psychopharmacology \& Biological Psychiatry, 49, 47-52.

Worthman, C. M., \& Konner, M. J. (1987). Testosterone levels change with subsistence hunting effort in ! Kung San men. Psychoneuroendocrinology, 12(6), 449-458.

Ziegler, T. E. (2000). Hormones associated with non-maternal infant care: a review of mammalian and avian studies. Folia Primatologica, 71(1-2), 6-21. 